carry their studies further. There are numerous illustrations in the form of either plates or line-drawings, but while the figures are to a very high standard, the photographs often leave much to be desired. Thus a plate claimed to be "witchweed on sorghum" is too reminiscent of an unkempt herbaceous border for real clarity, while the photograph of "downy mildew of onion" requires faith rather than good eyesight to assist interpretation. Nevertheless, this book has its virtues, not the least of which is that it is genuinely introductory in nature. Anybody with some knowledge of microorganisms will find this book a most painless meeting with what can be a complex and, if badly presented, tedious subject. Many students will find this account of plant diseases excellent vacation reading, and it could well provide a most valuable background of knowledge for laboratory courses.

R. K. RoBINSON

\section{SIX-LEGGED PESTS}

\section{Insects and Insecticides}

By R. C. Reay. (Contemporary Science Paperbacks, No. 39.) Pp. viii + 152. (Oliver and Boyd: Edinburgh, September 1969.) $7 s 6 d$.

Is this small book attention is focused only on insect pests. Part one (33 pages) therefore starts with a working definition of a pest in terms of a species eating man's food or drawing nourishment from man himself. This leads to descriptions of the types of insect mouthparts and the morphology and physiology of the gut. Part two (33 pages) is an unsatisfying rush through fourteen insect orders containing pest species, for it fails to emphasize, as intended, the diversity of their forms and habits. The third part ( 80 pages) describes the screening procedures for discovering new insecticides and then deals individually but briefly with a large number of the better known, old and new, insecticides. Synergists, formulation and mode of action of insecticides are mentioned, as are chemosterilants, attractants, repellents, and anti-feeding compounds; the text is up to date. Furthermore, biological, integrated and cultural methods of control are explained and the book concludes with five pages on the harmful effects of pesticides, against which the eight lines on the benefits are sadly out of proportion.

There is a sprinkling of errors of fact, but none is of serious consequence. Among the more aggravating details, however, are the use of double plurals, for example, sensillae, labellae, and of the extraordinary participle "parasited" (pages 131, 133). Scientific terms are liberally used without explanation, so that a reader without a fair knowledge of both entomology and chemistry could soon be in difficulties. This, allied to the general brevity of most of the comment, gives the impression that the book could well be based with little change on lecture notes for a course that could scarcely be compressed into the time available. It is hard to decide for whom the book is intended and the author offers no guide in his preface.

E. A. PARKIN

\section{VECTORS OF DISEASE}

\section{The Biology of Mosquito-borne Disease}

By P. F. Mattingly. (The Science of Biology Serics, No. 1.) Pp. xii + 184. (Allen and Unwin: London, October 1969.) Cloth $40 s$; paper $22 s$.

Twenty years ago, Marston Bates presented in his Natural History of Mosquitoes the then best review of available information on the physiology and ecology of mosquitoes and on their role as vectors of communicable disease. Much new knowledge has accumulated since that date and Mattingly's book attempts to bring together the most important recent developments in the field of mosquitoborne infections.
The title of the book does not indicate that it refers primarily to human diseases, although it mentions briefly the role of some animals as sources and reservoirs of the infective agent. The author describes these diseases as ecological systems involving the pathogen, the vector, the human host and the environment, and stresses the close interrelation between these main and several subsidiary factors. He then discusses the evolution and classification of malaria parasites, filarioid nematodes, viruses, and outlines their life histories and the involvement of human species in the epidemiological chain.

Four chapters cover the general systematies, physiology and behaviour patterns of the aquatic and winged stagos of mosquitoes; conditions affecting the contact of vectors with man, the responses of insects to insecticides, the methods of assessment of the activity of vectors and the basic principles of control are given much attention. There are two separate chapters on genetics of mosquitoes and on the problem of species-complexes. The final chapter on retrospects and prospects deals with the concept of eradication of mosquito-borne communicable disease and concludes that "ultimate weapons" offer promises that cannot be fulfilled; success is more likely to come from integrated approaches making the best use of weapons of every kind.

This book succeeds admirably in compressing into less than 200 pages a large amount of up to date information and gives a comprehensive picture of the host-parasite relationship in a group of infections influenced by the physical environment. In tracing the evolutionary background of arthropod-borne disease the author stresses the resilience of these systems in spite of man's attempt at breaking them. He also draws attention to the interest presented by mosquitoes as a subject for detailed biological study especially now when genetics, using resistance to insecticides as a convenient marker and when cytogeneties, allowing us to identify the "eryptic species", open new possibilities for research. The book discusses lucidly and perceptibly the ecological problems without calling the spade a "geotome" (to borrow one of Karl Schmidt's expressions), and it can be warmly recommended not only to advanced students or general biologists, but also to any specialist who does not mind reflecting on wider issues involved in some public health programmes.

A few minor blemishes are of little importance. There is a recurrent printing error in the sub-specific name of $P$. cynomolgi bastianellii named after Bastianelli and thus requiring a double $i$ at the end. In the chapter dealing with the biology of control and assessment of malaria the precise definition of the "reproduction rate" (an epidemiological concept) would be of value. The same applies to the term "vectorial capacity" which seems to have been misused in discussing mosquito genetics. There is no evidence that both the $A$ and $B$ species of $A$. gambiae became resistant to dieldrin simultaneously in 1955 , and the distribution of the latter Anopheles is much wider than only in Somalia and south-west Arabia. The list of sources omits unaccountably any reference to George Macdonald's pioneering work on quantitative epidemiology of malaria. The index could have been more complete.

The book is well and attractively produced on good quality paper with excellent line drawings and several well chosen photographs. $\quad$ L. J. Bruce-ChwatT

\section{BREEDING FOR WOOL}

\section{Quantitative Genetics in Sheep Breeding}

By Helen Newton Turner and Sydney S. Y. Young. Pp. 332. (Macmillan: Melbourne and London, July 1969.) A $\$ 20 ; 200 s$.

Wrthin the past two decades, attempts have been made to apply the principles of quantitative genetics to sheep improvement. Major contributions have come from the 